\title{
ОСОБЕННОСТИ ФОРМИРОВАНИЯ И ИСПОЛЬЗОВАНИЯ ЧЕЛОВЕЧЕСКОГО КАПИТАЛА В АГРАРНОМ СЕКТОРЕ, ЗАНЯТОСТЬ И ДОХОДЫ СЕЛЬСКОГО НАСЕЛЕНИЯ
}

\author{
(c) 2021 Пекуровский Дмитрий Александрович
}

кандидат ветеринарных наук, доцент кафедры управления АПК и сельскими территориями Российская академия кадрового обеспечения агропромышленного комплекса, Россия, Москва E-mail: pekurovskii@mail.ru

\author{
(c) 2021 Лебедев Александр Ларионович \\ кандидат технических наук, профессор, ректор \\ Международный экономико-гуманитарный институт, Россия, Москва \\ E-mail: a.lebedev@imegi.ru
}

(c) 2021 Семикова Ольга Руслановна

кандидат экономических наук, доцент, проректор по учебно-методической работе Международный экономико-гуманитарный институт, Россия, Москва

E-mail: semikova@imegi.ru

В статье рассматривается вопрос, затрагивающий интересы каждого государства - человеческий капитал, занятость и доходы населения. Идея человеческого капитала в истории экономической теории имеет особое значение как одна из составляющих факторов экономического роста страны, его аграрного сектора, в частности.

В статье исследованы взгляды отечественных учёных, изучавших вопросы занятости и доходы населения, а также воспроизводства и использования человеческого капитала.

Авторами рассмотрены основные современные концепции человеческого капитала, его сущность, тенденции и закономерности развития, представлены система управления человеческим капиталом. Раскрыты основные характеристики, принципы формирования и эффективного использования человеческого капитала в аграрном секторе экономики.

Отмечена закономерность взаимодействия предприятия и обладателя человеческого капитала, определены проблемы в формировании человеческого капитала и причины деградации человеческого капитала в аграрной сфере.

Обоснованы и предложены направления формирования и обеспечения эффективного использования человеческого капитала в аграрном секторе путём повышения занятости сельского населения, активизации инвестиционного обеспечения развития человеческого капитала.

Ключевые слова: человеческий капитал, аграрный сектор, формирование человеческого капитала, развитие, сельское хозяйство.

В современной аграрной экономике Российской Федерации вопросы по формированию и использованию человеческого капитала должны соответствовать требованиям нового типа развития сельскохозяйственного производства, которое можно охарактеризовать как эффективно используемое благодаря повышению качества производимой продукции и усилению кадрового потенциала, оперативной адаптацией к рыночным условиям, усиленной инновационной и предпринимательской мотивацией сотрудников $[1,12]$.

Актуальность темы исследования обуслов- лена необходимостью рассмотрения вопросов использования человеческого капитала, а также занятостью и доходами населения в аграрном секторе российской экономике.

При написании статьи были использованы труды отечественных учёных, это в частности: А.И.Добрынина, С.А. Дятлова, И. В. Игнашкиной, Е.В.Коваленко и Е.В. Овсянникова, Г.Ю.Пехтеревой, а также статистические данные Министерства сельского хозяйства Российской Федерации.

Следует отметить, что новые условия социально-рыночной экономики, ориентиро- 
ваны на переход к интенсивному типу развития, поэтому в этой связи крайне важна роль исследований по формированию и использованию человеческого капитала. Кроме того, для надлежащего развития современных производительных сил невозможно без формирования интеллектуальных и инновационно-информационных факторов, которые в совокупности способствуют консолидации социально-экономической роли человека в условиях аграрного сектора современной экономики.

Вместе с тем решение проблем в аграрном секторе требует разработки и внедрения новых подходов по использованию человеческого капитала, улучшения социальной сферы, что положительным образом скажется на повышении занятости работников и позволит увеличить инвестиции в человеческий капитал.

Следует подчеркнуть, что теория человеческого капитала и сформулированная на её базисе социально-экономическая политика является приоритетной сферой интересов государства, а также объединения предпринимателей в сфере аграрного комплекса, которая способна на основе созданной базу социального партнёрства успешно решать поставленные задачи.

Таким образом, только человеческий капитал, а не производственное оборудование и запасы, является экономически важной сферой как конкурентоспособность и экономический рост. Необходимо отметить, что концепция человеческого капитала имеет свои закономерности возникновения и исторические предпосылки, которые в итоге становятся предметом научных исследований $[2,14]$.

В настоящее время как теоретические, так и практические вопросы являются дискуссионными в научном сообществе и требуют тщательных исследований, особенно те, которые касаются особенностях воспроизводства и использования человеческого капитала в аграрном секторе экономики при условиях социально-рыночной среды.

Формирование профессиональных знаний и навыков в системе профессионального образования способствует приобретению новых качественных характеристик человека, от которых зависит увеличение производительности труда и доходов населения, в итоге и формирует человеческий капитал.

Трудовая деятельность на производстве в аграрном секторе экономики невозможно без наличия базовых знаний, умений и навыков, так как трудовой процесс продолжается в течение всей жизни гражданина, который постоянно получает образование и необходимый производственный опыт.

Новые знания и навыки позволяют лицу эффективнее использовать современное оборудование и технологии, поэтому процессы формирования и развития работника неотделимы друг от друга [14].

Человеческий капитал, выступая активным компонентом аграрной отрасли способен увеличивать уровень капитализации и выступать основным фактором, который обеспечит эффективное использование всей системы агропроизводства и сельских территорий включая все компоненты её структуры: начиная от фермерского хозяйства до предприятия по переработке продукции и отрасли, а в большем масштабе и отдельного региона и государства в целом.

Следует подчеркнуть, что вопросы формирования и развития человеческого капитала и процесс развития отрасли в сельском хозяйстве взаимозависимы. Неразрывна и связка человеческого капитала и науки с производственными технологиями, что влечёт за собой необходимость повышенных требований к профессиональному уровню работников при современных развитых производствах.

Исследуя систему формирования и развития человеческого капитала - следует отметить, что она включает в себя общность взаимосвязанных процессов, объектов и явлений, благодаря которым формируются кардинально новые социальные и производственные характеристики личности, занятой в аграрном комплексе Российской Федерации.

Характеризуя систему управления человеческим капиталом, следует отметить её структурные составляющие. Это, в частности, такие элементы, как:

1. Внешние факторы воздействия:

- государственное регулирование аграрного сектора экономики;

- экономические условия;

- политическая ситуация в государстве;

- технико-технологические нововведения;

- внешний рынок рабочей силы аграрного сектора.

2. Внутренние факторы воздействия:

- цели аграрного предприятия;

- организованная структура; 
- стиль руководства;

- организационная структура агропромышленного предприятия.

Систематизируя указанные выше структурные элементы, следует отметить, что первоначальное накопление человеческого капитала происходит в социально-культурной среде, в которой основной ячейкой является семья. Семья формирует для человека те базовые ценности, которые будут являться приоритетными в течение всей его жизни. Также важную роль на будущее человеческого капитала оказывают влияние школа и высшее учебное заведение, родители и социальная среда, окружающая человека.

Немаловажным является и фактор пропаганды здорового образа жизни, бережного отношения к экологии, стремление получить необходимое образование, которое будет способствовать накоплению профессионального потенциала работника, усилия по продвижению по карьерной и социальной лестнице.

Характеризуя количественно-качественные показатели человеческого капитала в сельском хозяйстве, следует отметить, что они формируются при воздействии условий и факторов, которые определяют качество человеческого капитала и сельского хозяйства страны в совокупности.

Таким образом, характеризуя конкурентоспособного работника аграрного сектора экономики, следует отметить, что это работник:

1. Обладающий необходимыми физиологическими способностями.

2. Применяющий в своей работе профессиональные теоретические знания и практические навыки.

3. Полученные знания и навыки работник применяет на конкретном предприятии аграрного сектора.

4. У работника имеется необходимая мотивация к труду в аграрной сфере.

5. Работник готов постоянно совершенствовать свои знания и навыки в условиях появления новых технологий и оборудования, машин и механизмов.

Рассмотрим факторы, которые оказывают непосредственное влияние на процесс формирования и использования человеческого потенциала в сельском хозяйстве.

На уровне предприятия капитализация происходит, прежде всего, за счёт усилий работодателя и индивидуума, направленных на развитие, накопление и эффективное использование че- ловеческого капитала.

Отмечается закономерность взаимодействия предприятия и носителя человеческого капитала - работника, которая заключается в том, что «чем богаче предприятие и чем больше средств оно может выделить на эти цели, тем результативнее будет и конкурентная борьба за привлечение квалифицированной рабочей силы [4].

Поэтому основные факторы развития человеческого капитала тесно связаны с возможностями предприятия направлять часть средств на эти цели. Среди них можно выделить - уровень развития производительных сил предприятия, оказывающий воздействие на человеческий капитал через необходимость взаимодействия с новой техникой, современным оборудованием, новыми приёмами организации производства, управления, маркетинга.

Так, в четырёх регионах России стартовал федеральный образовательный проект «Школа фермера» «Россельхозбанка». В число пилотных регионов вошёл Ставропольский край, Новосибирская и Московская области, Республика Башкортостан. «Школа фермера» позволит людям объединяться, создавать рентабельный бизнес, повышать уровень компетенций в сельском хозяйстве и получать удовольствие от своего труда. Это играет важную роль в подготовке кадров для субъектов малого и среднего бизнеса в сельском хозяйстве: Минсельхоз ожидает сохранения доли фермеров в производстве сельхозпродукции на уровне 14\% в текущем году и в дальнейшем рассчитывает на увеличение этого показателя.

Цель «Школы фермера» - научить желающих создавать и вести успешный бизнес в сельском хозяйстве. Проект предусматривает обучение передовым методам ведения бизнеса, повышение финансовой грамотности фермеров и получение практических навыков. Теоретическая часть обучения в «Школе фермера» включает в себя посещение занятий на базе аграрных вузов, а практические занятия позволят обучающимся перенять передовой опыт ведущих сельскохозяйственных производителей.

Что касается системы высшего аграрного образования в России, она позволяет эффективно наращивать кадровый и научный потенциал АПК страны, только в настоящее время Минсельхоз России осуществляет координацию деятельности 54 учреждений высшего образова- 
Таблица 1. Факторы, влияющие на процесс формирования и использования человеческого капитала в сельском хозяйстве

\begin{tabular}{|c|c|c|}
\hline Социально-экономические & $\begin{array}{c}\text { Технологические и инфраструк- } \\
\text { турные }\end{array}$ & Ресурсно-демографические \\
\hline Позитивные & Позитивные & Позитивные \\
\hline $\begin{array}{l}\text { - быстроразвивающийся рынок } \\
\text { сбыта; } \\
\text { - высокая степень экономической } \\
\text { и социальной освоенности терри- } \\
\text { тории; } \\
\text { - дальнейший рост объемов про- } \\
\text { изводства в АПК области; } \\
\text { - отлаженные торговые и внеш- } \\
\text { неэкономические связи; } \\
\text { - проведение мероприятий по } \\
\text { устойчивому развитию сельских } \\
\text { территорий; } \\
\text { - повышение эффективности } \\
\text { регулирования рынков сельскохо- } \\
\text { зяйственной продукции }\end{array}$ & $\begin{array}{l}\text { - технологическое и техническое } \\
\text { переоснащение материально- } \\
\text { технической базы и увеличение } \\
\text { уровня механизации сельхозпро- } \\
\text { изводства; } \\
\text { - создание инновационных цен- } \\
\text { тров и развитие их деятельности; } \\
\text { - создание новых оптовых } \\
\text { распределительных центров по } \\
\text { реализации сельхозпродукции; } \\
\text { - стимулирование инноваци- } \\
\text { онной деятельности и развития } \\
\text { сельского хозяйства }\end{array}$ & $\begin{array}{l}\text { - вовлечение в оборот неисполь- } \\
\text { зованных земель сельхозназначе- } \\
\text { ния; } \\
\text { - высокая освоенность агро- } \\
\text { ландшафтов и биоклиматический } \\
\text { потенциал; } \\
\text { - большие возможности развития } \\
\text { смежных производств на сельских } \\
\text { территориях и вовлечения в них } \\
\text { квалифицированной рабочей силы }\end{array}$ \\
\hline Негативные & & \\
\hline $\begin{array}{l}\text { - снижение численности работ- } \\
\text { ников и объёмов производства } \\
\text { в базовых отраслях сельского } \\
\text { хозяйства; } \\
\text { - недостаточно диверсифици- } \\
\text { рованная структура сельского } \\
\text { хозяйства; } \\
\text { - уровень оплаты труда и до- } \\
\text { ходов, темпы роста производи- } \\
\text { тельности труда существенно } \\
\text { ниже, чем в других производящих } \\
\text { отраслях; } \\
\text { - недостаточная эффективность } \\
\text { системы прогнозирования и пла- } \\
\text { нирования в сельском хозяйстве } \\
\text { - слабая кадровая политика, } \\
\text { неэффективная система профори- } \\
\text { ентации, подготовки и переподго- } \\
\text { товки кадров; } \\
\text { - низкий уровень престижа рабо- } \\
\text { ты в сельском хозяйстве }\end{array}$ & $\begin{array}{l}\text { - недостаточно продуманная } \\
\text { инновационная и инвестиционная } \\
\text { политика в отношении сельского } \\
\text { хозяйства; } \\
\text { - существенно худшие инфра- } \\
\text { структурные и транспортные усло- } \\
\text { вия по сравнению с городскими; } \\
\text { - относительная неразвитость } \\
\text { рыночной инфраструктуры и сбы- } \\
\text { товых возможностей товаропроиз- } \\
\text { водителей; } \\
\text { - недостаточный уровень раз- } \\
\text { вития социально-инженерной } \\
\text { инфраструктуры села; } \\
\text { - недостаточный качественный } \\
\text { уровень человеческого капитала; } \\
\text { - высокий уровень износа основ- } \\
\text { ных фондов; } \\
\text { - низкая инновационная актив- } \\
\text { ность в агропродовольственном } \\
\text { комплексе }\end{array}$ & $\begin{array}{l}\text { - невысокий уровень рождаемо- } \\
\text { сти; } \\
\text { - негативные темпы изменения } \\
\text { численности сельского населе- } \\
\text { ния; - повышенная миграционная } \\
\text { подвижность коренного населения } \\
\text { в направлении «село - город»; } \\
\text { - крайне высокие темпы при- } \\
\text { роста некоренных мигрантов в } \\
\text { сельское хозяйство области; } \\
\text { - пониженная степень эконо- } \\
\text { мической активности различных } \\
\text { социально-демографических } \\
\text { групп сельского населения; } \\
\text { - продолжающееся снижение } \\
\text { земельного плодородия; } \\
\text { - угроза трудовой экспансии со } \\
\text { стороны мигрантов }\end{array}$ \\
\hline
\end{tabular}

ния, которые ежегодно выпускают более 35 тыс. специалистов [9].

Использование современных подходов к образованию, развитие научно-технического потенциала, расширение международных связей и эффективное взаимодействие с бизнесом позволяют вузам Минсельхоза России удерживать статус региональных центров аграрной науки.

Подготовка специалистов осуществляется по таким направлениям, как агрохимия, почвоведение, экология, ветеринария, землеустройство, зоотехника, экономика аграрных предприятий, геодезия, сельскохозяйственная механизация, мелиорация [7, 20-25].

Система обучения учитывает в том числе все требования к подготовке квалифицированных специалистов, актуальные задачи по циф- ровой трансформации российского АПК, реализации комплексных научно-технических программ. Аграрные вузы страны располагают значительным материально-техническим, информационно-методическим и программным обеспечением, что позволяет им также вести научную деятельность, осуществлять фундаментальные и прикладные исследования, участвовать в разработке новых сортов и гибридов, селекционной работе.

Рассматривая задачи по повышению эффективного использования человеческого капитала, следует отметить следующее:

- инновационная стратегия развития предприятия стимулирует работников на повсеместное профессиональное развитие с дальнейшим получением высоких результатов в труде, а так- 
же поиску индивидуальных решений на возникающие производственные проблемы;

- уровень корпоративной культуры на предприятии АПК влияет на формирование личностных и профессиональных характеристик работников, способствует развитию совместного труда в коллективе на благо общего результата;

- развитие социальной инфраструктуры на предприятии, обеспечение надлежащих условий труда и охраны труда, развитие сферы досуга и быта, здравоохранения, физкультуры и спорта для сотрудников агросектора работников и членов их семей. В этой связи важно отметить фактор приближённости услуг социальной сферы и рабочих мест к месту проживания работников;

- уровень заработной платы (дохода) и занятости граждан на селе занимает первоочередное место при формировании человеческого капитала. Стабильная и высокая заработная плата является показателем уровня развития человеческого капитала и признаком его успешного применения;

- внедрение системы повышения квалификации позволяет развивать необходимые в производственном процессе знания и умения работника.

Исследуя доходы занятых в сельском хозяйстве работников, следует отметить тенденцию по их увеличению на 24\% за последние 5 лет. Данный фактор стал возможен благодаря политике импортозамещения, проводимой российскими властями. Кроме того, причинами роста доходов работников аграрного сектора, стали низкая конкуренция и развитие технологий [10, 12-19].

В перспективе аграрный сектор России переходит к высокотехнологичной и интеллектуальноёмкой сфере деятельности, что в свою очередь приведёт к дальнейшему росту заработных плат в отрасли. По состоянию на 2020 год, средняя заработная плата работника на селе составляет 32,7 тыс. рублей [8, 32-38].

Следует отметить, что в последние три года зарплаты аграриев поднимались особенно быстро благодаря программам импортозамещения, а государственная финансовая поддержка отрасли помогла повысить её рентабельность, а использование новых технологий привело к росту заработков. Технические специальности в сельском хозяйстве будут востребованы всё больше, при этом потенциал для продолжения этой тенденции сохраняется.
Спрос на высококвалифицированных специалистов агроотрасли нередко превышает предложение, так как в течение долгого времени выпускники высших сельскохозяйственных учебных заведений не шли работать по специальности из-за низких доходов, поэтому дефицит высококвалифицированных кадров в агросфере будет и дальше основным драйвером роста доходов.

Подчеркнём, что отраслевой человеческий капитал формируется за счёт влияния макропроцессов, оказывающих влияние на все отрасли.

Наиболее важными факторами здесь являются:

1. Демографические процессы, в частности снижение уровня рождаемости сказывается на количественных характеристиках состояния трудовых ресурсов. При этом влияние демографических процессов на рынок труда велико и отражаются на состоянии трудовых ресурсов только по прошествии определённого промежутка времени [5].

2. Интенсивность инвестиционных вложений в отрасль - уменьшение притока молодых квалифицированных перспективных кадров в отрасль, имеющих высокий уровень развития, обусловленное недостатком рабочих мест, неблагополучным социально-экономическим и инфраструктурным положением в сельской местности.

3. Нестабильный характер занятости, связанный с низкой рентабельностью отрасли, приводящей к сворачиванию производства и нередким банкротствам предприятий, в основном малых и средних [11, 32-35].

4. Социально ориентированное прямое финансирование из бюджета является одним из факторов выравнивания уровня жизни и экономического развития сельской местности. Рост пенсий, зарплаты бюджетникам позволяют сохранять и развивать сферу услуг, транспорта и связи, непроизводственного строительства.

5. Возможность получения качественного профессионального образования является одним из важнейших условий развития человеческого капитала в отрасли.

Вопросы формирования и развития человеческого капитала в сельскохозяйственных отраслях требуют дальнейшего изучения, поскольку большое влияние на его формирование и использование оказывают природный фак- 
тор и землепользование, сезонность сельскохозяйственного производства; необходимость широкого совмещения выполняемых трудовых процессов и сельскохозяйственных работ; неблагоприятные социально-экономические условия жизни сельского населения [6, 25-27].

Для повышения качества и эффективности использования человеческого капитала в сельском хозяйстве и на аграрных предприятиях необходимо проведение стимулирующей инвестиционной и социальной политики.

В заключение следует отметить, что стратегическим ресурсом развития аграрного сектора становится человеческий капитал, сущность которого приобретает новый смысл. Возникает необходимость в разработке действенного социально-экономического механизма его формирования и использования.

Таким образом, можно сделать следующие выводы:

- большую роль в развитии современной аграрной экономики играет человеческий капитал в сельском хозяйстве, накопленный запас здоровья, способностей, знаний, квалификации, трудового опыта. Отдельными видами человеческого капитала являются капитал здоровья, культурно-нравственный капитал, трудовой, интеллектуальный, социальный, организацион- ный и структурный;

- важной особенностью человеческого капитала в сельском хозяйстве является большое воздействие на его формирование и использование природного фактора, землепользования, сезонности, необходимости широкого совмещения профессий и выполняемых работниками производственных процессов;

- в целом качество человеческого капитала в сельском хозяйстве в настоящее время достаточно низкое вследствие многолетнего отставания этой отрасли АПК, запущенности социальной сферы села, слабой государственной поддержки аграрного сектора;

- для повышения качества человеческого капитала в сельском хозяйстве, необходимо существенно увеличить доходы работников, развить социальную сферу села, улучшить условия труда на основе комплексной механизации сельскохозяйственного производства, обеспечить неуклонное повышение квалификации работников;

- основным источником доходов, используемых для воспроизводства человеческого капитала в сельском хозяйстве в современных условиях, выступают доходы от личного подсобного хозяйства сельских жителей.

\section{Библиографический список}

1. Добрынин А.И. Мировой экономический кризис и трансформация рыночной модели хозяйства - «Известия Иркутской государственной экономической академии»-№6, 2018, с.5-15

2. Дятлов С.А.Инвестиции в человеческий капитал России: состояние, проблемы, перспективы: монография - СПб, 2020, с.216

3. Игнашкина И.В., Коваленко Е. В. Формирование и использование человеческого капитала в аграрном секторе экономики - «Вестник Омского государственного аграрного университета» - № 7, 2015, с.90-97

4. Овсянников Е. В. Воспроизводство и использование человеческого капитала в сельском хозяйстве: автореф. дис. ... канд. эконом. наук - Курск, 2017, с.19

5. Пехтерева Г.Ю. Человеческий капитал работников сельского хозяйства: автореф. дис. ... канд. эконом. наук - Орёл, 2016, с.24

6. Пучков Б. П. Сельская занятость: нужны не столько деньги, сколько оригинальные решения - «Человек и труд» - № 8, 2020, с.25-27

7. Серова Е.В., Звягинцев Д.В. Альтернативная занятость в сельской местности - «Мир России» - № 4, 2019, c. $20-25$

8. Тихонова Т.Л, Шик О.М.Доходы работников аграрной отрасли в сельской местности России - «Вестник ВШЭиУ» - № 7, 2020, с.32-38

9. Росстат: статистический сборник- «Труд и занятость в России»-2019

10. Ушачев И. Д. Основные направления социально-экономического развития АПК - «Экономист» - № 6,2020 , c. 12-19

11. Храмова И.Г. Сельская бедность и сельское развитие в России - «ИЭПП» - 2016, с.32-35.

12. Dudin M.N., Lyasnikov N. V., Sekerin V.D., Gorokhova A.E. HISTORICAL ASPECTS OF GLOBAL TRANSFORMATION OF ENGINEERING THOUGHT IN INDUSTRY AND AGRICULTURE IN THE CONTEXT OF CHANGING THE TECHNOLOGICAL MODES // American-Eurasian Journal of Sustainable Agriculture. 2014. T. 8. № 6. C. 17-22 
13. Sekerin V.D., GorokhovaA.E., Dudin M.N., Shibanikhin E.A., BalkizovM.H. GREEN BUILDING: TECHNOLOGIES, PROSPECTS, INVESTMENT ATTRACTIVENESS // International Journal of Civil Engineering and Technology. 2018. T. 9. № 1. C. 657-666

14. Trubilin A.I., GaydukV.I., Belkina E.N., KalitkoS.A., GorokhovaA.E. INFRASTRUCTURE OF THE REGIONAL AGRIFOOD MARKET: PECULIARITIES OF FUNCTIONING AND METHODS OF IMPROVEMENT // Espacios. 2017. T. 38. № 33. C. 41 